\title{
APLICAÇÃO DO MASP PARA REDUÇÃO DE RETRABALHOS - ESTUDO DE CASO EM UMA INDÚSTRIA DE COMUNICAÇÃO VISUAL
}

\section{MASP APPLICATION FOR REDUCTION REWORKS - CASE STUDY ON A VISUAL COMMUNICATION INDUSTRY}

\author{
Mario Henrique Bueno Moreira Callefi; Daiane Maria de Genaro Chiroli²; \\ ${ }^{1}$ Universidade Estadual de Maringá - UEM - Maringá/PR - Brasil \\ mariocallefi@gmail.com \\ ${ }^{2}$ Universidade Estadual de Maringá - UEM - Maringá/PR - Brasil \\ dmgenaro@hotmail.com
}

\begin{abstract}
Resumo
O mercado da comunicação visual está cada mais competitivo, gerando assim a necessidade de apresentar preços mais competitivos e possuir padrões de qualidade que estejam de acordo com os requisitos da qualidade impostos pelo mercado. Dessa maneira para as empresas conseguirem sobreviver no mercado atual é necessário que os custos sejam reduzidos, principalmente com as atividades que não agregam valor junto ao cliente, como é o caso das ocorrências de não conformidades. O presente trabalho por meio da utilização da Metodologia de Análise e Solução de Problemas (MASP), com base na etapa de planejamento do ciclo PDCA, objetivou-se em analisar as ocorrências de retrabalhos e permitir a elaboração de um plano de ação para a resolução desse problema. Ferramentas da qualidade como o $5 \mathrm{WlH}$, gráfico de Pareto, diagrama de causa e efeito foram empregadas como apoio para o uso do MASP. Como resultado foi desenvolvido um plano de ação que permitirá que a empresa direcione suas atividades com foco na melhoria contínua e na eliminação de seus problemas de qualidade.
\end{abstract}

Palavras-chave: MASP, qualidade, ferramentas da qualidade, ciclo PDCA.

\section{Introdução}

Com o aumento da competitividade do mercado da comunicação visual, as empresas do setor necessitam diferenciar-se no mercado. De acordo com Quinteiro (2006), as organizações no contexto atual da globalização e a revolução tecnológica, são imputadas a atualizarem seus processos e valores, devido a ampliação dos desafios enfrentados junto ao mercado empresarial.

Entre as características vitais que definem a probabilidade de uma empresa sobreviver no cenário econômico atual é a capacidade de oferecer produtos e serviços que se adequam as necessidades do cliente, tanto no quesito custo como na qualidade. Segundo Carpinetti (2012), para qualquer empresa que tem o desejo de se manter competitiva e conquistar uma fatia maior de mercado, prioritariamente necessita antes de tudo, atender os requisitos dos clientes quanto a 
produtos e serviços, pois a satisfação do mesmo gera para o negócio: boa reputação, novos pedidos, faturamento, lucro, empregos e outras vantagens.

A partir das práticas da gestão da qualidade é possível reduzir desperdícios e custos da não qualidade no processo de produção, consequentemente é possível reduzir preços, pois na lógica atual do mercado ganha quem apresentar os preços mais baixos ao mesmo tempo em que consiga cumprir os requisitos pré-estabelecidos pelo consumidor (CARPINETTI, 2012).

Campos (2014) destaca que o ganho de produtividade é consequência da relação de produzir mais, ou melhor, com cada vez menos. Seguindo essa lógica é possível definir que a ocorrência de retrabalhos em uma organização, gera perdas de produtividade, ocasionando na redução do lucro.

Para Deming (1990) o custo de retrabalho é apenas uma consequência do custo ocasionado por problemas relacionados com a não qualidade, a existência de clientes insatisfeitos que podem transmitir sua frustração para conhecidos, gerando assim também percas para o negócio, sendo essas imensuráveis.

Segundo Moraes (2010), a Metodologia de Analise e Solução de Problemas - MASP é um método que tem por objetivo localizar as causas fundamentais de problemas, buscando eliminar ou minimizar seus efeitos, por meio da por meio da coleta, analise, agrupamento e estratificação de dados.

A empresa em estudo tem sede em Maringá e atua na aérea de comunicação visual, elaborando e executando os mais complexos projetos de imagem no setor automobilístico, bancário, petroleiro, pneus, distribuição, telefonia, alimentício, atacadista, varejista, industrial, dentre outros.

$\mathrm{O}$ alto índice de retrabalho apresentado pela empresa vem causando dificuldades, pois os custos aumentam e os lucros diminuem. Por meio do MASP será possível analisar as causas relacionadas com a alta taxa de retrabalhos, a partir de dados levantados entre janeiro de 2014 a dezembro de 2014 e elaborar um plano de ação visando a redução do problema tanto na instalação externa, como em todos os setores da empresa.

Este estudo tem por objetivo realizar a análise de dados históricos de retrabalhos e propor um plano de ação para resolução do problema em uma em empresa do ramo da comunicação visual por meio da aplicação do MASP.

\section{Revisão bibliográfica}

Neste capítulo são apresentados os conceitos de Qualidade, Gestão da Qualidade, PDCA, MASP e as ferramentas da qualidade.

\subsection{Gestão da Qualidade}


Para Campos (2014) produtos ou serviços de qualidade são aqueles que conseguem adequarse perfeitamente nas necessidades dos consumidores de maneira confiável, acessível, segura e no momento certo. Qualidade é uma ligação da organização com os consumidores, ou seja, essa ligação apresenta a relação de consumo, consequentemente a qualidade apresenta-se como um fator de liderança estratégica das organizações (CARVALHO e PALADINI, 2012).

Segundo Oakland (1994), a definição de qualidade como atendimento das exigências dos clientes não é reservada apenas aos atributos funcionais dos produtos ou serviços, mas expande-se ao valor da satisfação da posse, ou seja, os requisitos são tão bem atendidos, que estabelecem uma reputação de excelência ao produto ou serviço.

Oliveira (2003) define que a Gestão da Qualidade tem por objetivo a eliminação ou redução das atividades que não agregam valor ao produto. Para Carpinetti et al. (2011) a Gestão da Qualidade é essencial para as organizações no que se refere a estratégia competitiva e seu objetivo pode ser desdobrado em dois conceitos, conquistar mercados e reduzir desperdícios.

A primeira metade do século foi marcada pela qualidade limitada ao processo de fabricação, por meio da inspeção e controle dos processos produtivos, a partir da década de 50, os conceitos de gestão da qualidade ganharam notoriedade, difundindo-se para todo o ciclo de operação, abrangendo a organização como um todo (CARPINETTI, 2012).

Para Paladini (2006) um aspecto importante sobre a Gestão da Qualidade é a "adequação ao uso", onde todos os elementos que formam a organização e que tem alguma participação, seja diretamente ou indiretamente no processo produtivo, têm responsabilidade pela qualidade, tornando os produtos ou serviços adequados aos consumidores e em relação ao ambiente industrial, as práticas da Gestão da Qualidade atuam em especial no processo produtivo, no qual se podem conceber produtos "adequados ao uso", ou seja, a qualidade manifestada no produto é a resposta do processo.

Dentro do contexto da Gestão da Qualidade, é imprescindível tratar dos conceitos do TQC e do TQM já que esses conceitos segundo Bueno (2003), apresentam uma estrutura que permitem o envolvimento de toda organização, com o objetivo de alcançar a qualidade total.

Para Carvalho e Paladini (2012) o TQC ou Controle da Qualidade Total baseia-se no comprometimento com a qualidade total por todas as pessoas da organização, tendo como fator decisivo para seu sucesso, a liderança do processo, gerida pela alta gerencia.

Segundo Campos (2014) o TQC pode ser definido como um sistema administrativo otimizado no Japão, com base nos conceitos americanos de qualidade que tem por objetivo envolver todas os funcionários e setores de uma organização no planejamento e na condução do controle de 
qualidade, ou seja, o controle total é desempenhado por todos na organização, de forma sistêmica e fundamentada no ciclo PDCA.

O controle da qualidade total no estilo japonês é caracterizado por seis características essenciais: Envolvimento de toda organização com o controle da qualidade total, desenvolver um sistema de treinamento e conscientização, desenvolvimento de tarefas relacionadas ao círculo de controle de qualidade, realização de auditorias e participação no prêmio Deming de Qualidade, utilização de modelos estatísticos da qualidade e ferramentas da qualidade e por último a realização de campanhas nacionais para conscientização da importância da qualidade.

Segundo Carpinetti (2012), o TQM ou Gestão da Qualidade Total em português, pode ser considerado como uma estratégia de negócios que tem como alvo fazer empresas se tornarem mais competitivas, com base na melhoria continua da qualidade dos serviços, processos, produtos, ambiente e pessoas.

Segundo Carvalho e Paladini (2012) o TQM define que a qualidade deve estar inclusa na função de gerenciamento organizacional, objetivando que a as ações relacionadas a qualidade, não fiquem somente ligada na parte do controle, os elementos presentes no TQM são apresentados pelo Quadro 1.

Quadro 1 - MASP com base na etapa de planejamento do ciclo PDCA

\begin{tabular}{|c|l|}
\hline \multicolumn{2}{|c|}{ ELEMENTOS DO TQM } \\
\hline Elemento & \multicolumn{1}{c|}{ Descrição } \\
\hline $\begin{array}{c}\text { Liderança e apoio da } \\
\text { alta direção }\end{array}$ & $\begin{array}{l}\text { Prover liderança no processo de mudança, exemplaridade e motivação da força de } \\
\text { trabalho da organização. Deve também promover e estimular as práticas e abordagens } \\
\text { direcionadas ao TQM. }\end{array}$ \\
\hline $\begin{array}{c}\text { Relacionamentos } \\
\text { com os clientes }\end{array}$ & $\begin{array}{l}\text { Concentrar as atividades com foco nos clientes e estabelecer canais de comunicação, } \\
\text { visando a levantar suas necessidades e níveis de satisfação, promovendo um } \\
\text { entendimento sobre os clientes. }\end{array}$ \\
\hline $\begin{array}{c}\text { Gestão da força de } \\
\text { trabalho }\end{array}$ & $\begin{array}{l}\text { Aplicar os princípios de gestão de recursos humanos, com base em um sistema de } \\
\text { trabalho em equipe e com empowerment, processos de recrutamento e seleção, e } \\
\text { capacitação e treinamento. }\end{array}$ \\
\hline $\begin{array}{c}\text { Relação com os } \\
\text { Fornecedores }\end{array}$ & $\begin{array}{l}\text { Utilizar as Práticas de seleção e qualificação de fornecedores, bem como meios de } \\
\text { medição de desempenho. Estabelecer relação de longo prazo com os fornecedores } \\
\text { visando à colaboração mútua, além de buscar melhoria da qualidade dos produtos. }\end{array}$ \\
\hline $\begin{array}{c}\text { Gestão por } \\
\text { Processos }\end{array}$ & $\begin{array}{l}\text { Definir os processos-chave da organização, promover práticas preventivas, auto } \\
\text { inspeção, utilizando planos de controle e utilização de métodos estatísticos na produção. }\end{array}$ \\
\hline $\begin{array}{c}\text { Projeto de Produto } \\
\text { Fatos e dados da } \\
\text { qualidade }\end{array}$ & $\begin{array}{l}\text { Envolver todas as aéreas funcionais no processo de desenvolvimento de produto, } \\
\text { visando a desenvolver um produto que venha a satisfazer aos requisitos dos clientes. }\end{array}$ \\
\hline $\begin{array}{l}\text { Disponibilizar os dados e informações relativas à qualidade, como parte de um sistema } \\
\text { de gestão transparente e de fácil visualização. Registros sobre os indicadores da } \\
\text { qualidade, incluindo índices de refugo, retrabalho, dados de garantia, custos da } \\
\text { qualidade. }\end{array}$ \\
\hline
\end{tabular}

Fonte: Adaptado. Carvalho e Paladini (2012, p. 95)

O Quadro 1 abrange os conceitos que compõem o TQM, a análise desses elementos permite que seja feito uma avaliação inicial da situação atual da empresa em relação a Gestão da Qualidade. 


\subsection{PDCA (Plan-Do-Check-Act)}

O ciclo PDCA que é conhecido também como de ciclo de Shewhart ou ainda ciclo de Deming, permite que a execução da gestão da qualidade seja feita de uma maneira mais rápida e clara (DAYCHOUM, 2007).

Para Werkema (1995) o ciclo PDCA pode ser classificado como uma ferramenta de gestão, onde a partir dele são definidos caminhos que serão percorridos pela organização, objetivando alcançar as metas definidas, esse caminho é feito com o suporte de diversas ferramentas da qualidade, que auxiliam no levantamento e análise dos dados.

Entre as técnicas ou ferramentas mais utilizadas como suporte a execução estão as sete ferramentas da qualidade, confiabilidade, análise multivariada, análise de variância, análise de regressão, planejamento de experimentos, otimização de processos, entre outros (WERKEMA, 1995).

Campos (2014) destaca que o ciclo PDCA é empregado para a manutenção do nível de controle, em casos que os processos são repetitivos e também na melhoria do nível do controle, quando o processo não é repetitivo.

Segundo Carpinetti (2012), a metodologia mais genérica no que se refere ao processo de melhoria continua é o ciclo PDCA, sendo composto de quatro etapas, conforme na Figura 1:

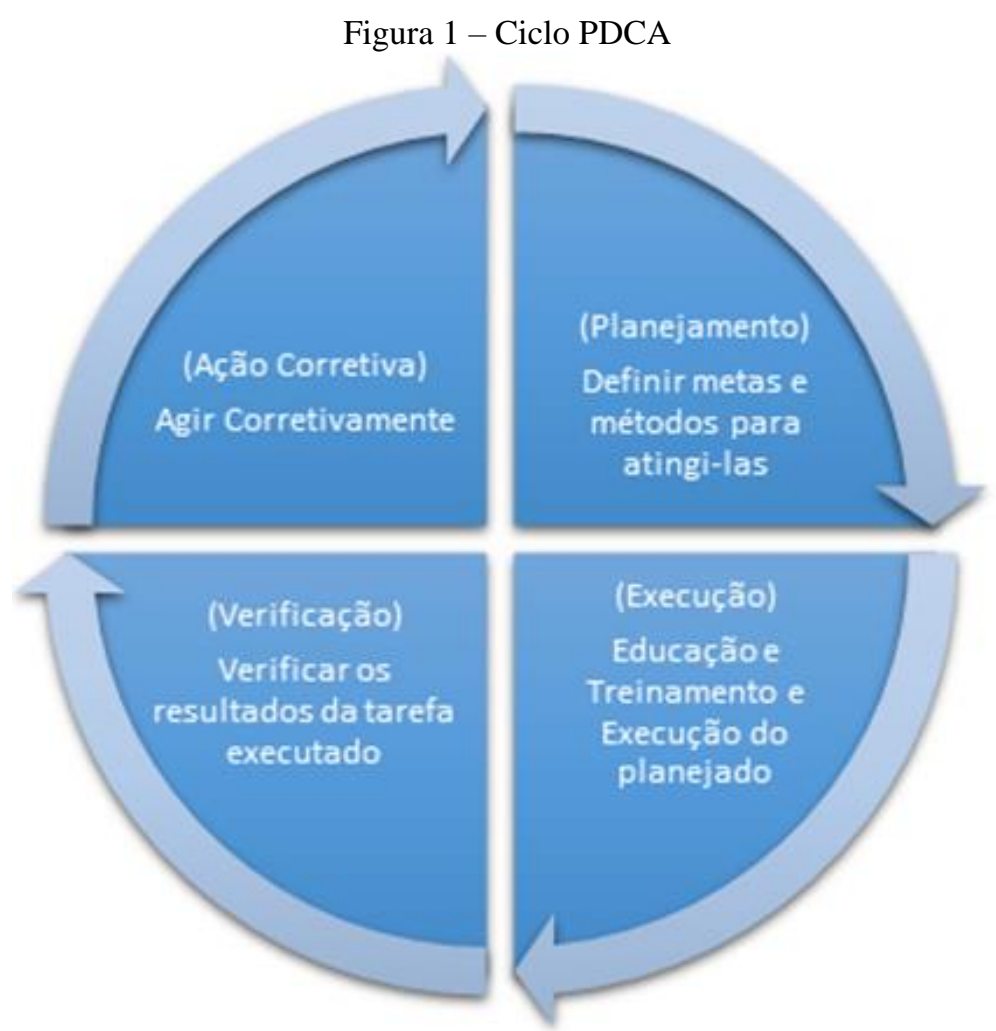

Fonte: Carpinetti (2012, p.39). 
Aguiar (2012) qualifica o ciclo PDCA como uma ferramenta essencial para as organizações alcançarem meta, que consequentemente garantiram sua manutenção no mercado, sendo que o mesmo possui quatros etapas:

- Planejamento (Plan): etapa onde ocorre a definição do que será feito e a elaboração de estratégias para atingir as metas estabelecidas;

- Execução (Do): etapa onde ocorre o treinamento e execução de tarefas, conforme definido na etapa de planejamento;

- Verificação (Check): etapa onde ocorre o levantamento de dados do que foi executado anteriormente, objetivando a verificação do comprimento das metas;

- Ação Corretiva (Action): etapa em que é verificado o atingimento das metas, sendo que a partir da identificação das metas não alcançadas é necessária a elaboração de um novo planejamento das ações de melhoria, dando reinicio ao ciclo PDCA.

\subsection{Método de Análise e Solução de Problemas - MASP}

Toledo (2001 apud Ribeiro e Piedade, 2009) apresenta o MASP como um método prático que abrange diversas ferramentas de controle que permitem que problemas sejam identificados e as suas causas raízes possam ser localizadas, com o objetivo de que planos de ações possam ser elaborados para a solução de problemas. Já segundo Costa e Hora (2009 apud Costa et al., 2012) o MASP (Metodologia de Análise e Solução de Problemas) é uma metodologia que com base no ciclo PDCA que permite a análise e soluções de problemas.

Para Campos (2014), a metodologia MASP é essencial para a implantação do controle de qualidade, sendo parte do próprio método de controle e torna-se necessário para qualquer organização que todos os envolvidos tenham capacidade de resolver problemas.

O MASP é de total importância para a elaboração de ações corretivas em que as empresas necessitem investigar o impacto dos problemas relacionados no que se referem a riscos, custos e benefícios (CERQUEIRA, 1995).

De acordo com Carpinetti (2012), o MASP ou QC Story como é conhecido no Japão, apresenta as seguintes fases, de acordo com Figura 2. 
Figura 2 - Etapas do MASP

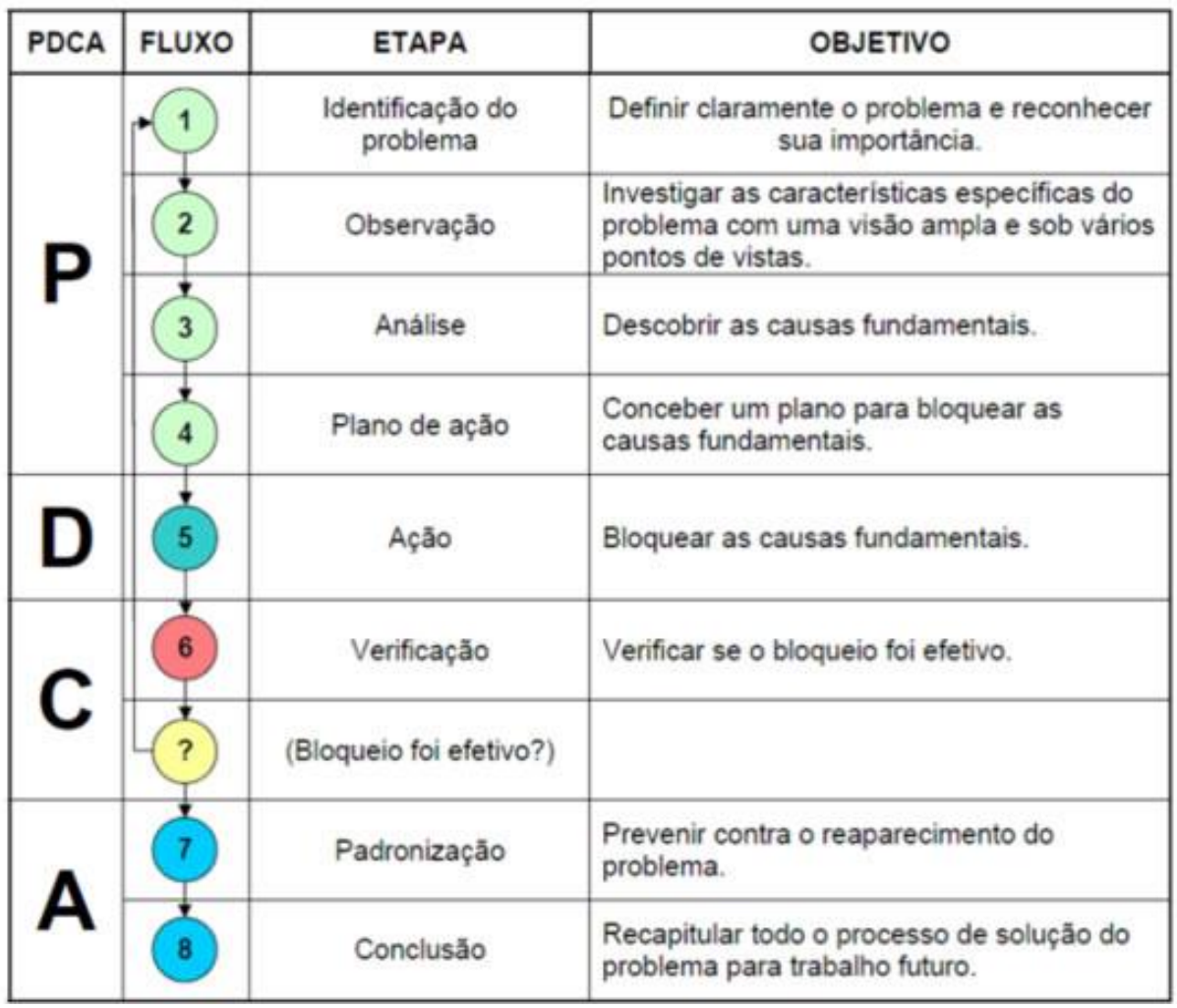

Fonte: Carpinetti (2012, p.40).

O MASP é composto de oito fases, de acordo com a Figura 2, sendo elas:

- Identificação do Problema: Nessa fase, procura-se identificar os problemas mais críticos e, portanto, mais prioritários;

- Observação: objetiva a caracterização completa do problema para aumentar a chance de se identificar as causas do problema;

- Análise: nessa fase, busca-se levantar as causas raízes ou fundamentais do problema em questão;

- Plano de ação: depois de identificadas as supostas causas fundamentais; o objetivo desta fase é elaborar e detalhar um plano de ação para a eliminação dos efeitos indesejáveis das causas fundamentais. Ou seja, objetiva-se bloquear as causas fundamentais;

- Ação: consiste na implementação do plano de ação;

- Verificação: Consiste na avaliação de resultados para a verificação se ação foi eficaz na eliminação ou minimização do problema. Caso o resultado não tenha sido satisfatório, o processo é reiniciado pela observação e análise do problema. Caso contrário, seguese para a próxima etapa;

- Padronização: visa introduzir as ações implementadas na rotina de operação do processo ou atividade, de forma a prevenir o reaparecimento do problema;

- Conclusão: o processo é finalizado com o registro de todas as ações empreendidas e resultados obtidos, para posterior recuperação de informações e históricos. (CARPINETTI, 2012, P.40-41).

\section{Procedimentos metodológicos}

O tipo de pesquisa do presente trabalho é de natureza exploratória, tem como objetivo o desdobramento de ideias e o levantamento hipóteses mais corretas para um estudo mais preciso (HONORATO, 2014). 
Quanto aos procedimentos técnicos, essa pesquisa pode ser classificada como estudo de caso, dado que para Gil (2008), um estudo de caso se baseia no estudo aprofundado de um ou poucos objetos, permitindo a análise detalhada de suas características.

Para o estudo de caso, foi necessário avaliar dados primários, relacionados ao setor de Planejamento e Controle de Produção e Qualidade da empresa. Esses dados são do histórico do período de janeiro até dezembro de 2014. Para analisar o problema observado por meio de coleta de dados fez-se a utilização das ferramentas da qualidade apresentadas no capítulo anterior.

A aplicação do MASP será apenas com base na etapa de planejamento do ciclo PDCA, ou seja, abrangem as quatro primeiras etapas do MASP, conforme apresentado pelo Quadro 2.

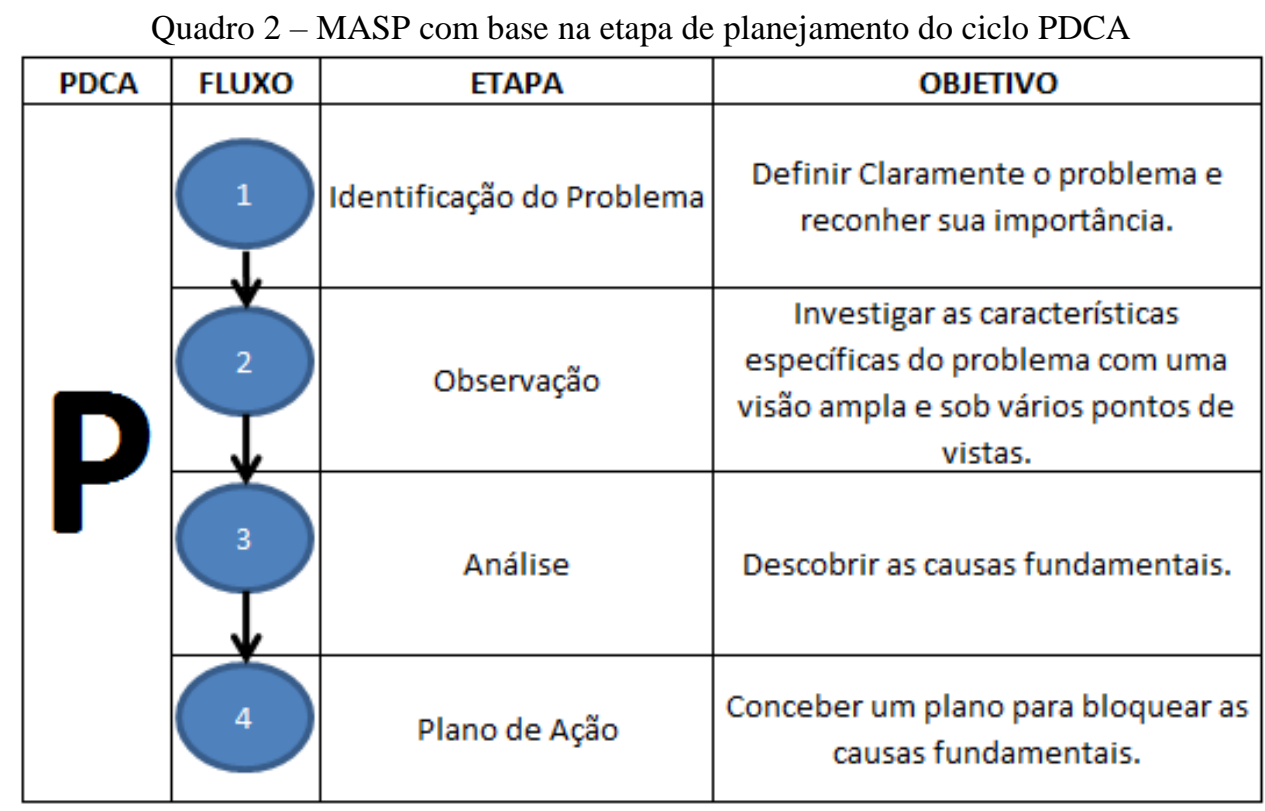

Fonte: Adaptado. Carpinetti (2012, p. 40).

Nas etapas de identificação do problema e Observação que compõem a metodologia MASP, foi realizada a caracterização do problema, identificando os impactos mais críticos do alto índice de retrabalho.

$\mathrm{Na}$ etapa de análise, os dados coletados foram analisados com o auxílio de ferramentas da qualidade como o diagrama de causa e efeito, Brainstorming e o Gráfico de Pareto visando levantar as causas fundamentais do alto índice de retrabalhos.

Na etapa de plano de ação do MASP, com o auxílio da ferramenta $5 \mathrm{~W} 1 \mathrm{H}$, foi elaborada uma estratégia para combater as causas raízes do problema, objetivando a redução do índice de retrabalho.

\section{Análise dos dados e proposta de plano de ação}

Nesta seção temos a contextualização da empresa, a avaliação da Gestão da Qualidade na empresa e a execução da metodologia MASP conforme definido na Seção 3. 


\subsection{Contextualização da Empresa}

A empresa em estudo atua no mercado a mais de 35 anos e conta com uma matriz localizada na cidade de Maringá-PR e duas unidades filiais uma localizada em Maringá-PR e outra em Cabo de Santo Agostinho-PE, totalizando uma área total de aproximadamente $25.000 \mathrm{~m}^{2}$, sendo $14.000 \mathrm{~m}^{2}$ de área construída.

Em dias atuais com 250 funcionários diretos, distribuídos nas três instalações e tem como ramo de negócio a comunicação visual, onde atua no desenvolvimento de projetos e aplicação de tecnologias de ponta na fabricação de diversos produtos para o mercado de comunicação corporativa, seja de elementos externos, internos e mobiliários. Entre os clientes atendidos pela empresa estão grandes redes varejistas, shoppings, rede de bancos, rede de postos de gasolina, aeroportos, empresas do setor automobilístico, dentre outros.

\subsection{Avaliação da Gestão da Qualidade}

Em primeiro passo para o desenvolvimento do estudo foi realizado a avaliação da Gestão da Qualidade onde se baseou nos elementos do TQM de Carvalho e Paladini (2012), conforme descrito no item 2.1.

As ações praticadas pela empresa estão voltadas apenas nas atividades de controle, no entanto, limita-se ao uso do indicador de retrabalhos e visa cumprir os objetivos e requisitos da qualidade. Em outras palavras, existe a preocupação com aspectos relacionados com a Qualidade,mas não existem métodos e práticas na rotina da empresa que abranjam conceitos de melhoria contínua da qualidade, planejamento da qualidade e garantia de qualidade.

O setor de qualidade da empresa é composto apenas por quatro pessoas e fica responsável pela manutenção de máquinas, modificação do layout e pela elaboração das RNC'S - Registro de Não Conformidades, que tem como função identificar as ocorrências de retrabalho. Já a avaliação da qualidade dos produtos em produção ou acabados dentro da empresa é realizada pela gerência e pelos líderes de cada setor em que o material passa. Além disso, a verificação da qualidade do material após a instalação final é responsabilidade de um engenheiro de campo, que por meio de um relatório com fotos, realizações de medições necessárias e da assinatura do cliente, comprovam a integridade do material instalado.A empresa possui uma estratégia ineficaz de resolução de problemas relacionados com não conformidades, já que quando existe a reclamação por meio de um cliente da inconformidade de algum produto, o mesmo é imediatamente trocado, sendo assim, não é realizada nenhuma análise das causas raízes, impossibilitando a elaboração de ações corretivas em outras peças em produção. 
O controle de qualidade atual diverge bastante dos conceitos do TQC, pois não existe o envolvimento de toda organização com o tema e nem qualquer treinamento ou conscientização para o desenvolvimento de tarefas real acionadas ao círculo de qualidade.

Em relação ao TQM, não existe preocupação com a melhoria contínua da qualidade. $\mathrm{O}$ Quadro 3 apresenta a situação da empresa atual em relação aos elementos do TQM:

Quadro 3 - Elementos do TQM na Empresa Estudada

\begin{tabular}{|c|l|}
\hline Elemento & \multicolumn{1}{c|}{ Descrição } \\
\hline $\begin{array}{c}\text { Liderança e apoio } \\
\text { da alta direção }\end{array}$ & $\begin{array}{l}\text { A alta direção não apoia no processo de mudança e pouco investe nas } \\
\text { práticas e abordagens direcionadas ao TQM }\end{array}$ \\
\hline $\begin{array}{c}\text { Relacionamentos } \\
\text { com os clientes }\end{array}$ & $\begin{array}{l}\text { O relacionamento com os clientes é restringindo apenas ao atendimento } \\
\text { após a finalização, em que caso a peça instalada apresente algum problema, } \\
\text { o cliente pode solicitar algum reparo. }\end{array}$ \\
\hline $\begin{array}{c}\text { Gestão da força } \\
\text { de trabalho }\end{array}$ & $\begin{array}{l}\text { Não existe um sistema de trabalho em equipe e nem com empowerment. o } \\
\text { processo de recrutamento e seleção é básico, sem qualquer planejamento e } \\
\text { não existem práticas de capacitação e treinamento da força de trabalho. }\end{array}$ \\
\hline $\begin{array}{c}\text { Relação com os } \\
\text { Fornecedores }\end{array}$ & $\begin{array}{l}\text { A relação com os fornecedores é limitada apenas ao momento da compra, } \\
\text { não existindo qualquer comunicação posterior a compra. Os fornecedores } \\
\text { não são qualificados, nem existe estabelecimento de uma relação de longo } \\
\text { prazo com os fornecedores. }\end{array}$ \\
\hline $\begin{array}{c}\text { Gestão por } \\
\text { Processos }\end{array}$ & $\begin{array}{l}\text { Os processos-chave são definidos, mas não existem práticas preventivas, } \\
\text { auto inspeção, utilização de planos de controle e nem a utilização de } \\
\text { métodos estatísticos na produção. }\end{array}$ \\
\hline $\begin{array}{c}\text { Projeto de } \\
\text { Produto }\end{array}$ & $\begin{array}{l}\text { No desenvolvimento de novos produtos, existe o envolvimento de todas as } \\
\text { aéreas funcionais da empresa, com o objetivo de desenvolver um produto } \\
\text { que satisfaça os requisitos dos clientes. }\end{array}$ \\
\hline $\begin{array}{c}\text { Fatos e dados da } \\
\text { qualidade }\end{array}$ & $\begin{array}{l}\text { Não existe muitos dados levantados relativos a qualidade, as únicas } \\
\text { informaçães registradas são referentes as ocorrências de retrabalho. }\end{array}$ \\
\hline
\end{tabular}

Fonte: Autor.

O Quadro 7 abrangeu os conceitos que compõem o TQM, em relação a situação em dias atuais da indústria de Comunicação Visual estudada e a partir disso, pode-se caracterizar a abordagem em relação a qualidade praticada, distante dos conceitos do TQM, TQC e Gestão da Qualidade, já que as práticas adotadas, são focadas na inspeção e na resolução de problemas imediatos, sem planejamento.

Com a análise das práticas de Gestão da qualidade apresentada anteriormente, temos que apenas a inspeção não é suficiente para resolução do problema do alto nível de retrabalho, mas, é preciso definir um processo de análise mais criteriosa dos retrabalhos de produtos acabados, o qual vai permitir a empresa localizar as causas-raízes dos problemas e assim garantir a diminuição de custos de não qualidade e o desgaste com os clientes. 
A empresa diante do cenário apresentado de alto índice de retrabalho e da utilização de práticas ineficazes de gestão de qualidade torna-se necessário padronizar processos e produtos e também definir de uma maneira mais concreta os processos de avaliação e controle como o objetivo de atender às necessidades dos clientes. A utilização do MASP é essencial para analisar o problema da ocorrência de retrabalhos, permitindo identificação e avaliação das causas raízes e a definição de um plano de ação que possibilitará a padronização e controle do processo e produto.

\subsection{Execução da metodologia MASP}

Conforme apresentado na metodologia, a execução do MASP no presente trabalho será com base na fase de planejamento do Ciclo PDCA, onde serão seguidas quatro etapas: identificação do problema, observação do problema, análise do problema e elaboração do plano de ação.

\subsubsection{Identificação do problema}

A partir da análise de dados das ocorrências de retrabalho e do faturamento da empresa, observou-se que apenas os custos de matéria-prima gastos com não conformidades equivalem a aproximadamente $1 \%$ do faturamento e $3 \%$ do lucro líquido. Considerando os gastos de mão de obra, transporte e instalação das peças defeituosas como sendo o dobro do valor de matéria prima, temos que a empresa tem um prejuízo de aproximadamente $3 \%$ do faturamento e $12 \%$ do lucro líquido. Desde modo a empresa perdeu em 2014 mais de um décimo de seu lucro líquido, demonstrando o impacto do problema para a empresa e o quanto é necessário elaborar alguma forma de combatê-lo.

Por meio da análise da Tabela 1 é possível perceber que os produtos produzidos para os clientes $\mathrm{C} 1, \mathrm{C} 2, \mathrm{C} 3, \mathrm{C} 4$ e C5 representam juntos mais de $70 \%$ dos custos com retrabalho do ano de 2014 e também 36,9\% das vendas nesse mesmo ano. A Tabela 1 apresenta a relação entre os gastos com retrabalho e total vendido por cliente no ano de 2014 para esses cinco clientes.

Tabela 1 - Relação do gasto com retrabalho com o total vendido por cliente em 2014

\begin{tabular}{|c|c|c|c|}
\hline CLIENTE & $\begin{array}{c}\text { PORCENTAGEM } \\
\text { CUSTO DE } \\
\text { RETRABALHO }\end{array}$ & $\begin{array}{c}\text { PORCENTAGEM VENDA POR } \\
\text { CLIENTE }\end{array}$ & $\begin{array}{c}\text { GASTOS COM } \\
\text { RETRABALHO POR } \\
\text { CLIENTE/ TOTAL } \\
\text { VENDIDO POR CLIENTE }\end{array}$ \\
\hline C1 & $36.48 \%$ & $4.53 \%$ & $5.34 \%$ \\
\hline C2 & $15.61 \%$ & $25.23 \%$ & $0.41 \%$ \\
\hline C3 & $7.89 \%$ & $3.49 \%$ & $1.50 \%$ \\
\hline C4 & $5.35 \%$ & $2.47 \%$ & $1.44 \%$ \\
\hline C5 & $5.28 \%$ & $1.17 \%$ & $3.00 \%$ \\
\hline TOTAL & $70,62 \%$ & $\mathbf{3 6 , 9 0 \%}$ & - \\
\hline
\end{tabular}

Fonte: Autor 
$\mathrm{Na}$ Tabela 1 temos que os custos de retrabalho com os produtos do cliente $\mathrm{C} 1$ representam $5,34 \%$ do total comprado pelo cliente em 2014 e a partir dessas informações e também pela significância do cliente na história recente da empresa, o cliente $\mathrm{C} 1$ foi identificado como o cliente de maior importância para empresas. Para a resolução dos problemas relativos aos produtos produzidos para esse cliente, será realizado as demais etapas do MASP definidas na metodologia do presente trabalho.

\subsubsection{Observação do problema para o cliente $\mathrm{C} 1$}

O cliente $\mathrm{C} 1$ é uma das principais redes de concessionárias e montadora de automóveis do país. A empresa foco deste estudo produz os seguintes itens para o cliente em questão: logomarca, pórtico, totem, fachada, placa de departamento, revestimento de ACM, entre outros, no total de 30 tipos de itens. Tabela 2 traz informações sobre a quantidade de itens vendidos e de ocorrências de retrabalho para cada produto do cliente $\mathrm{C} 1$.

Tabela 2 - Porcentagem de ocorrências de retrabalho para o total de vendas por item em 2014

\begin{tabular}{|c|c|c|c|}
\hline ITEM & ITENS VENDIDOS & OCORRÊNCLAS RETRABALHO & $\begin{array}{c}\% \text { ITENS VENDIDOS } \\
\text { / OCORRÊNCLAS } \\
\text { RETRABALHO }\end{array}$ \\
\hline LOGOMARCA & 32 & 19 & $59,38 \%$ \\
\hline PORTICO & 16 & 4 & $25,00 \%$ \\
\hline PLACA DE DEPARTAMENTO & 15 & 0 & $0,00 \%$ \\
\hline TOTEM & 11 & 3 & $27,27 \%$ \\
\hline FACHADA & 5 & 1 & $20,00 \%$ \\
\hline REVESTIMENTO ACM & 4 & 0 & $0,00 \%$ \\
\hline OUTROS & 8 & 0 & $0,00 \%$ \\
\hline
\end{tabular}

Fonte: Autor

Concluindo a etapa de observação do MASP, temos que pelas informações apresentadas na Tabela 2, a logomarca foi o item com maior quantidade de ocorrências de retrabalho para o cliente $\mathrm{C} 1$ e que do total de itens vendidos aproximadamente $60 \%$ apresentaram problemas em alguma parte do processo. Portanto a logomarca foi observada como o item mais crítico e que necessita de maior atenção, devido ao alto índice de ocorrência de retrabalhos. A etapa de análise do MASP será executada com objetivo de encontrar as causas fundamenteis do problema. 


\subsubsection{Análise do problema}

A logomarca do cliente $\mathrm{C} 1$ é fabricada há vários anos pela empresa, sendo um dos itens mais fabricados anualmente e o processo produtivo consiste das seguintes operações, conforme descrito na Figura 3:

Figura 3 - Processo produtivo da logomarca do cliente $\mathrm{C} 1$

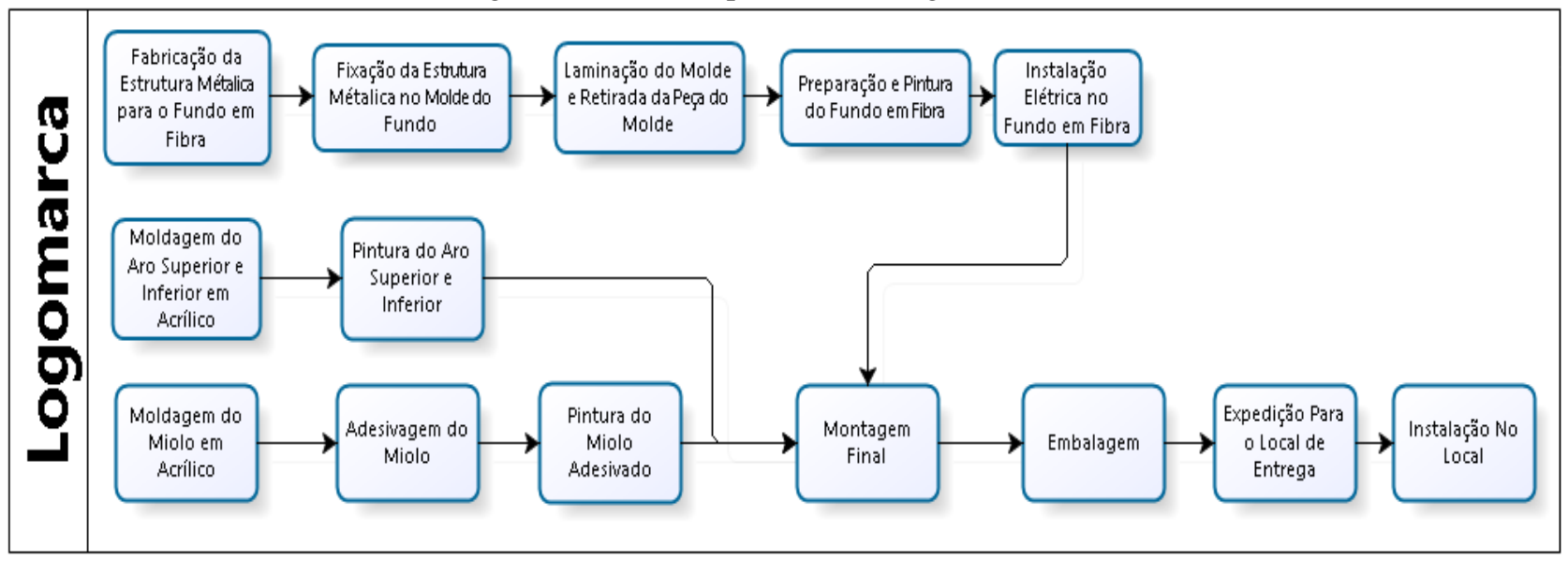

Fonte: Autor

Como podemos ver na Figura 3, o processo é subdivido em 14 atividades: fabricação da estrutura metálica para o fundo da fibra, fixação da estrutura metálica no molde do fundo, laminação do molde e retirada da peça do molde, preparação e pintura do fundo em fibra, instalação elétrica do fundo em fibra, moldagem do aro superior e inferior em acrílico, pintura do aro superior e inferior, moldagem do miolo em acrílico, adesivagem do miolo, pintura do miolo adesivado, montagem final, embalagem, expedição para o local de entrega e a instalação no local. $\mathrm{O}$ entendimento do processo produtivo da logomarca apresentado na Figura 3 é essencial para localizar quais são as causas fundamentais do problema, já que se pode analisar em quais etapas do processo ocorrem determinadas ocorrências de retrabalho, permitindo assim também a elaboração de um plano de ação mais detalhado para a resolução de problemas. Na Figura 4 é apresentado o gráfico de Pareto, o qual comtempla o desdobramento das ocorrências de retrabalho da logomarca do cliente c1 em 2014: 
Figura 4 - Gráfico de Pareto - Desdobramento das Ocorrências de Retrabalho da Logomarca

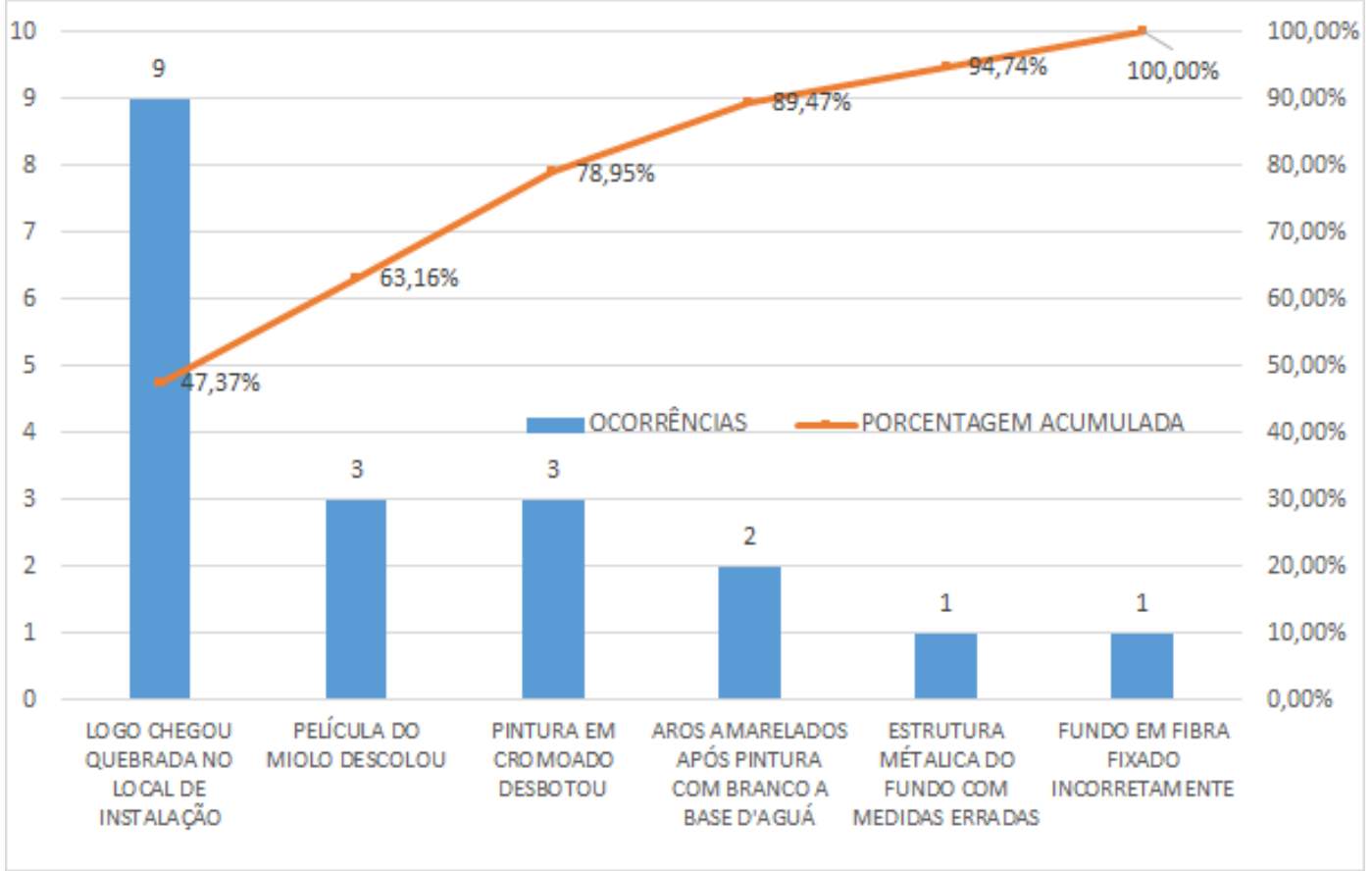

Fonte: Autor

A partir da Figura 4 temos que os três principais problemas são: quebra da logomarca no transporte para o local de instalação, descolamento da película do miolo da logomarca após a instalação e o desbotamento da pintura cromo do miolo e dos aros. Para identificar as causas raízes desses problemas é necessário a realização do Brainstorming com a gerência e os líderes de cada setor.

Para encontrar as causas raízes do problema da quebra da logomarca no transporte foi realizado um Brainstorming com o responsável do acrílico e o gerente industrial. As causas levantadas foram: chapa de acrílico de baixa qualidade, espessura da chapa de acrílico incorreta e falta de experiência do responsável por carregar e descarregar o material.

Em relação as causas raízes do problema do descolamento da película do miolo da logomarca foi realizado um Brainstorming com o responsável da película e o gerente industrial. Entre as causas levantadas temos uso de película de baixa qualidade, vedação incorreta da logomarca e adesivagem incorreta.

As causas raízes do problema do desbotamento da pintura cromo do miolo e dos aros foi realizado um Brainstorming com o responsável da pintura e o gerente industrial. A utilização de tinta cromo fora do padrão e uso de pigmento da tinta fora do padrão, foram as causas identificadas para esse problema. A partir da constatação dessas causas raízes é possível definir um plano de ação para combatê-las. 


\subsubsection{Plano de ação para resolução do problema}

Com o uso da ferramenta da qualidade $5 \mathrm{~W} 1 \mathrm{H}$ e a realização de um Brainstorming com o gerente industrial e os líderes dos setores envolvidos, foi elaborado um plano de ação para combater as causas do problema da quebra da logomarca no transporte. O Quadro 4 apresenta o plano de ação para as causas raízes das ocorrências de quebras da logomarca no transporte.

Quadro 4 - Plano de ação - quebra da logomarca no transporte

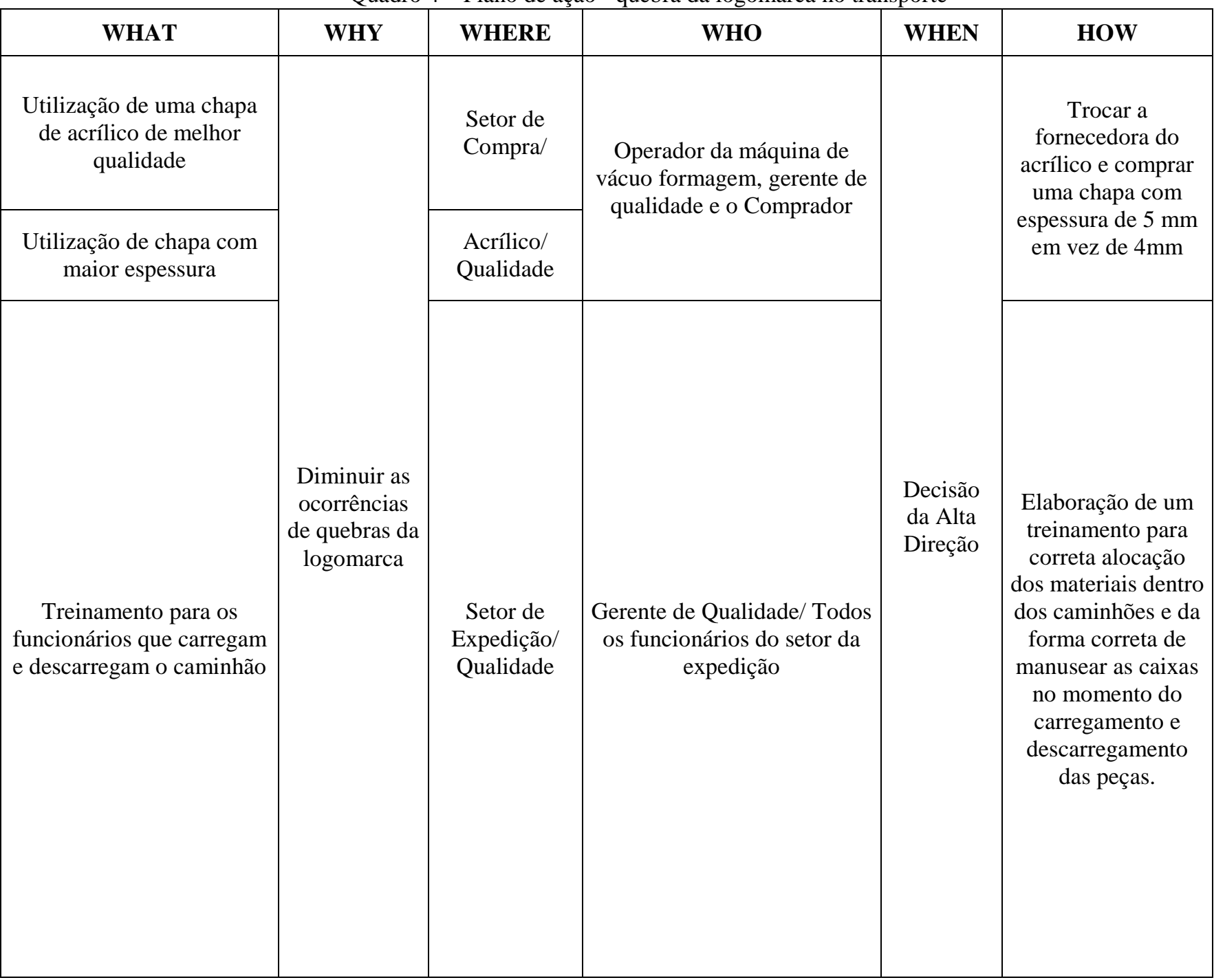

Fonte: Autor

A partir da execução do plano de ação apresentado no Quadro 4 é possível reduzir ou extinguir o problema da quebra da logomarca no transporte. O Quadro 5 apresenta o plano de ação para as causas raízes do problema de descolamento da película do miolo da logomarca: 
Quadro 5 - Plano de ação - descolamento da película da logomarca

\begin{tabular}{|c|c|c|c|c|c|}
\hline WHAT & WHY & WHERE & WHO & WHEN & HOW \\
\hline $\begin{array}{l}\text { Homologação de uma película de } \\
\text { um novo fornecedor }\end{array}$ & & $\begin{array}{l}\text { Comprador/ } \\
\text { Gerente da } \\
\text { Qualidade }\end{array}$ & $\begin{array}{c}\text { Operador da } \\
\text { máquina de vácuo } \\
\text { formagem, gerente } \\
\text { de qualidade e o } \\
\text { Comprador }\end{array}$ & & $\begin{array}{l}\text { Homologar junto ao } \\
\text { cliente uma película } \\
\text { de outro fornecedor }\end{array}$ \\
\hline $\begin{array}{c}\text { Verificação da logomarca após a } \\
\text { montagem final para garantir a } \\
\text { correta vedação da peça }\end{array}$ & & $\begin{array}{l}\text { Setor de } \\
\text { Montagem } \\
\text { Interna/ } \\
\text { Qualidade }\end{array}$ & $\begin{array}{c}\text { Gerente de } \\
\text { Qualidade/ Líder } \\
\text { do setor de } \\
\text { montagem interna }\end{array}$ & & $\begin{array}{c}\text { Elaboração de } \\
\text { verificações a após o } \\
\text { término da montagem } \\
\text { da peça, para garantir } \\
\text { a integridade da } \\
\text { mesma. Visando } \\
\text { garantir a correta } \\
\text { vedação da peça }\end{array}$ \\
\hline $\begin{array}{l}\text { Padronização do processo de } \\
\text { adesivagem da logomarca e } \\
\text { treinamento para os funcionários } \\
\text { que adesivam a logomarca }\end{array}$ & $\begin{array}{c}\text { Diminuir as } \\
\text { ocorrências } \\
\text { de } \\
\text { deslocamento } \\
\text { da película } \\
\text { da logomarca }\end{array}$ & $\begin{array}{l}\text { Setor de } \\
\text { Qualidade/ } \\
\text { Película }\end{array}$ & $\begin{array}{c}\text { Gerente de } \\
\text { Qualidade/ Líder } \\
\text { do setor de } \\
\text { película }\end{array}$ & $\begin{array}{l}\text { Decisão } \\
\text { da Alta } \\
\text { Direção }\end{array}$ & $\begin{array}{c}\text { Elaborar um padrão } \\
\text { que define as ações } \\
\text { corretas para } \\
\text { adesivação da } \\
\text { logomarca e } \\
\text { treinamento de todos } \\
\text { os funcionários do } \\
\text { setor de película } \\
\text { visando que os } \\
\text { mesmos aprendam e } \\
\text { sigam o padrão } \\
\text { estabelecido para o } \\
\text { processo }\end{array}$ \\
\hline
\end{tabular}

Fonte: Autor

Por meio da execução do plano de ação apresentado no Quadro 5 é possível reduzir ou extinguir o problema do deslocamento da película da logomarca. O Quadro 6 apresenta o plano de ação para as causas raízes do problema de desbotamento da pintura cromo do miolo e dos aros da logomarca.

\begin{tabular}{|c|c|c|c|c|c|}
\hline WHAT & WHY & WHERE & WHO & WHEN & HOW \\
\hline $\begin{array}{l}\text { Teste de qualidade da } \\
\text { tinta cromo antes do } \\
\text { início da pintura do } \\
\text { material }\end{array}$ & \multirow{2}{*}{$\begin{array}{l}\text { Diminuir as } \\
\text { ocorrências de } \\
\text { desbotamento } \\
\text { da pintura } \\
\text { cromo do miolo } \\
\text { e dos aros. }\end{array}$} & $\begin{array}{l}\text { Setor de } \\
\text { Qualidade/ } \\
\text { Pintura }\end{array}$ & $\begin{array}{l}\text { Gerente de Qualidade/ } \\
\text { Líder do setor de pintura }\end{array}$ & \multirow[t]{2}{*}{$\begin{array}{l}\text { Decisão } \\
\text { da Alta } \\
\text { Direção }\end{array}$} & $\begin{array}{l}\text { Realização de testes de } \\
\text { qualidade para verificar } \\
\text { que a tinta cromo } \\
\text { fabricada está de acordo } \\
\text { com a formulação padrão }\end{array}$ \\
\hline $\begin{array}{l}\text { OS pigmentos devem } \\
\text { ser testados antes do } \\
\text { início da produção da } \\
\text { tinta }\end{array}$ & & $\begin{array}{l}\text { Setor de } \\
\text { Qualidade/ } \\
\text { Pintura }\end{array}$ & $\begin{array}{l}\text { Gerente de Qualidade/ } \\
\text { Líder do setor de pintura/ } \\
\text { Responsável pela } \\
\text { produção da tinta }\end{array}$ & & $\begin{array}{c}\text { Realização de teste de } \\
\text { qualidade e verificação da } \\
\text { validade dos pigmentos } \\
\text { que compõem a tinta } \\
\text { cromo }\end{array}$ \\
\hline
\end{tabular}

Fonte: Autor 


\title{
5. Considerações Finais
}

O presente trabalho teve como objetivo a identificação das principais causas das ocorrências de retrabalho na empresa estudada, a metodologia MASP foi utilizada como fundamento realizar a análise e identificação das causas raízes do problema. A partir do MASP elaborou-se um plano de ação que permite a redução de não conformidades por meio de ações corretivas das causas raízes.

A utilização do MASP tornou viável que os objetivos gerais e específicos fossem atingidos, já que por meio da realização das etapas de identificação do problema, observação do problema, análise do problema e elaboração do plano de ação foi possível analisar dados históricos do setor de PCP e qualidade da empresa, realizar o desdobramento das principais causas do problema e por fim elaborar uma proposta de ações para solucionar o problema em questão.

\begin{abstract}
The market of visual communication is becoming more competitive, thus creating the need to provide more competitive prices and have quality standards that comply with the quality requirements imposed by the market. This way for businesses manage to survive in the current market it is necessary that the costs are reduced, especially with activities that do not add value from the customer, as is the case of occurrences of non-compliance. This work through the use of Analysis and Problem Solving Methodology (MASP), based on the PDCA cycle planning stage aimed to analyze the occurrences of reworks and enable the preparation of an action plan for resolution this problem. Tools such as the quality $5 \mathrm{~W} 1 \mathrm{H}$, Pareto chart, cause and effect diagram were used as support for the use of MASP. As a result, we developed a plan of action that will allow the company to direct its activities with a focus on continuous improvement and the elimination of its quality problems.
\end{abstract}

Key-words: MASP, quality, quality tools, PDCA cycle.

\section{Referências}

AGUIAR, S. Integração das ferramentas da qualidade ao PDCA e ao programa Seis Sigma. Nova Lima: INDG, 2012.

CAMPOS, V. F. Controle da qualidade total (no estilo japonês). 9. ed. Nova Lima: Editora Falconi, 2014.

CARPINETTI, L. C. R. Gestão da qualidade: conceitos e técnicas. 2. ed. São Paulo: Atlas, 2012.

CARPINETTI, L. C. GEROLAMO, M. C.; R; MIGUEL, P. A. C. Gestão da qualidade ISO 9001:2008: princípios e requisitos. 4. ed. São Paulo: Atlas, 2011.

CARVALHO, M. M.; PALADINI, E. P. (Coord.). Gestão da qualidade: teoria e casos. 2. ed. Rio de Janeiro: Elsevier: ABEPRO, 2012.

CERQUeIRA. J. P. A Metodologia de Análise e Solução de Problemas. 1. ed. São Paulo: Pioneira, 1995.

COSTA, H. G.; HORA, H. R. Tomada de decisão no MASP: uma contribuição para decisões utilizando a matriz AHP. In: XXIX Encontro Nacional de Engenharia de Produção, Salvador, Anais..., 2009.

COSTA, N. N.; MARÇAL, L. L.; SILVA, A. C. A. aplicação do MASP, utilizando o ciclo PDCA na solução de problemas no fluxo de informações entre o PPCP e o almoxarifado de uma fábrica de refrigerantes para o abastecimento 
de tampas plásticas e rolhas metálicas. In: XXVIII Encontro Nacional de Engenharia de Produção, Rio de Janeiro, Anais... Rio de Janeiro: ABEPRO, 2008.

DAYCHOUM, M. 40 ferramentas e técnicas de gerenciamento. 1. ed. Rio de Janeiro: Brasport, 2007.

DEMING, W.E. Qualidade: a revolução da administração. 1. ed. Rio de Janeiro: Marques-Saraiva, 1990.

GIL. A. C. Como elaborar projetos de pesquisa. 4. ed. São Paulo: Atlas, 2008.

HONORATO. G. Conhecendo o marketing. 1. ed. Barueri: Manole, 2004.

MORAES, G. Elementos do Sistema de Gestão de SMSQRS - Vol. 2 - Sistema de Gestão Integrada. 2. ed. Rio de Janeiro: GVC, 2008.

OAKLAND, J. Gerenciamento da qualidade total. São Paulo: Nobel, 1994.

OLIVEIRA, O. J. (org.). Gestão de qualidade: tópicos avançados. São Paulo: Pioneira, 2004.

PALADINI, E. P. Gestão de qualidade: teoria e prática. 1. ed. São Paulo: Atlas, 2006.

RIBEIRO, L. M.; PIEDADE, A. R. Aplicação do método de análise e solução de problemas (MASP) no varejo de carne bovina em Itapetininga/SP. Revista Sapere, Tatuí, v. 2, n. 1, jun 2010.

QUINTEIRO, E. A. Um sensível olhar sobre o terceiro setor. 1. ed. São Paulo: Summus, 2006.

WERKEMA, M. C. C. As Ferramentas de qualidade no gerenciamento de processos - Volume 1. Belo Horizonte: Fundação Cristiano Otoni, Escola de Engenharia da UFMG, 1995.

TOLEDO, J.C. Gestão da qualidade na agroindústria. In: BATALHA, M.O (Coord.) et al. Gestão AgroindustrialVolume. 2. São Paulo: Atlas, 2001. p.488-495.

\section{Dados dos autores:}

Nome completo: Mario Henrique Bueno Moreira Callefi

Graduado em Engenharia de Produção pela UEM

Filiação institucional: Universidade Estadual de Maringá

Departamento: Engenharia de Produção

Função ou cargo ocupado: Engenheiro de Produção

Endereço completo para correspondência: Av. Colombo, 5790 Jd. Universitário Maringá-Pr-Brasil CEP 87020-900

E-mail: mariocallefi@gmail.com

Nome completo: Daiane Maria De Genaro Chiroli

Doutora em Engenharia de Produção pela UFSC

Filiação institucional: Universidade Estadual de Maringá

Departamento: Engenharia de Produção

Função ou cargo ocupado: Professor Adjunto

Endereço completo para correspondência: Av. Colombo, 5790 Jd. Universitário Maringá-Pr-Brasil CEP 87020-900

E-mail:dmgenaro@hotmail.com

Submetido em: 21-07-2016

Aceito em: 21-09-2016 